\title{
The Importance of the NRG-1/ErbB4 Pathway for Synaptic Plasticity and Behaviors Associated with Psychiatric Disorders
}

\author{
Alon Shamir, ${ }^{\star}$ Oh-Bin Kwon, ${ }^{*}$ Irina Karavanova, Detlef Vullhorst, Elias Leiva-Salcedo, Megan J. Janssen, \\ and Andres Buonanno \\ Section on Molecular Neurobiology, Eunice Shriver Kennedy National Institute of Child Health and Human Development, Bethesda, Maryland 20892
}

\begin{abstract}
Neuregulin 1 (NRG-1) and its receptor ErbB4 have emerged as biologically plausible schizophrenia risk factors, modulators of GABAergic and dopaminergic neurotransmission, and as potent regulators of glutamatergic synaptic plasticity. NRG-1 acutely depotentiates LTP in hippocampal slices, and blocking ErbB kinase activity inhibits LTP reversal by theta-pulse stimuli (TPS), an activity-dependent reversal paradigm. NRG-1/ErbB4 signaling in parvalbumin (PV) interneurons has been implicated in inhibitory transmission onto pyramidal neurons. However, the role of ErbB4, in particular in PV interneurons, for LTP reversal has not been investigated. Here we show that ErbB4-null $\left(\mathrm{ErbB}^{-/-}\right)$and PV interneuron-restricted mutant (PV-Cre;ErbB4) mice, as well as NRG-1 hypomorphic mice, exhibit in-

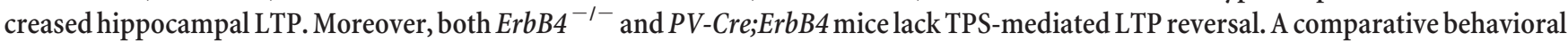
analysis of full and conditional ErbB4 mutant mice revealed that both exhibit hyperactivity in a novel environment and deficits in prepulse inhibition of the startle response. Strikingly, however, only $E r b B 4^{-1-}$ mice exhibit reduced anxiety-like behaviors in the elevated plus maze task and deficits in cued and contextual fear conditioning. These results suggest that aberrant NRG-1/ErbB4 signaling in PV interneurons accounts for some but not all behavioral abnormalities observed in $E r b B 4^{-1-}$ mice. Consistent with the observation that $P V$-Cre;ErbB4 mice exhibit normal fear conditioning, we find that ErbB4 is broadly expressed in the amygdala, largely by cells negative for PV. These findings are important to better understand ErbB4's role in complex behaviors and warrant further analysis of ErbB4 mutant mice lacking the receptor in distinct neuron types.
\end{abstract}

\section{Introduction}

Maintaining the balance between excitation and inhibition is important for the homeostatic control of normal brain function and behavior, and imbalances are believed to contribute to the pathology of multiple psychiatric disorders, including schizophrenia (Benes and Berretta, 2001; Coyle, 2006; Kehrer et al., 2008; Lisman et al., 2008). Recent rodent work from several laboratories suggests that the schizophrenia risk genes Neuregulin 1 $(N R G-1)$ and ERBB4 may play an important role in regulating hippocampal and frontal cortical pyramidal neurons (for review,

\footnotetext{
Received April 15, 2011; revised Dec. 27, 2011; accepted Jan. 9, 2012.

Author contributions: A.B. designed research; A.S., 0.-B.K., I.K., E.L.-S., and M.J.J. performed research; A.S. 0.-B.K., I.K., D.V., E.L.-S., M.J.J., and A.B. analyzed data; D.V. and A.B. wrote the paper.

This work was supported by the NICHD intramural program (to all authors). We thank Drs. Cary Lai and Kent Loyd for the floxed ErbB4 mouse strain, Dr. Novak for the NRG-1 ${ }^{\Delta E F}$ mouse strain, and Dr. Hongkui Zeng for the ErbB4-2A-CreERT2 mouse strain. We are grateful to Daniel Abebe for expert assistance with mouse husbandry, to Drs. Vincent Schram and Carolyn Smith from the NICHD and NINDS microscopy core facilities for expert assistance with microscopy, and to Dr. Joerg Neddens for critical reading of the manuscript.

${ }^{*}$ A.S. and O.B.K. contributed equally to this work.

Correspondence should be addressed to Dr. Andres Buonanno, Section on Molecular Neurobiology, Building 35, Room 2C-1000, 35 Lincoln Drive, National Institutes of Health, Bethesda, MD 20892-3714. E-mail: buonanno@mail.nih.gov.

A. Shamir's present address: Mazra Mental Health Center, Akko, Israel.

0.-B. Kwon's present address: Molecular NeuroScience Lab, Department of Life Science, Pohang University of Science and Technology, Pohang, South Korea.

DOI:10.1523/JNEUROSCI.1899-11.2012

Copyright $\odot 2012$ the authors $\quad 0270-6474 / 12 / 322988-10 \$ 15.00 / 0$
}

see Mei and Xiong, 2008; Buonanno, 2010), while disrupted NRG-1/ErbB4 signaling perturbs neuronal network activity (Fisahn et al., 2009; Nason et al., 2011), consistent with the notion of schizophrenia representing a disorder of functional connectivity and synaptic plasticity (Stephan et al., 2006).

Acutely administered NRG-1 peptide blocks or reverses LTP at Schaeffer collateral-to-CA1 (SC $\rightarrow$ CA1) glutamatergic synapses in the hippocampus (Huang et al., 2000; Kwon et al., 2005; Bjarnadottir et al., 2007). Conversely, pharmacological blockade of ErbB receptor activity prevents LTP reversal by theta-pulse stimuli (TPS), which model a naturally occurring neural activity pattern in the hippocampus (Stäubli and Chun, 1996), suggesting that neural activity recruits the NRG/ErbB pathway to antagonize synapse strengthening (Kwon et al., 2005). While ErbB4, the main neuronal NRG receptor, is expressed in several interneuron subtypes in the cerebral cortex, it is not detected in pyramidal neurons (Vullhorst et al., 2009; Neddens and Buonanno, 2010; Neddens et al., 2011), indicating that NRG/ErbB effects on synaptic plasticity are mediated via local circuit mechanisms.

Parvalbumin (PV)-expressing fast-spiking basket cells are especially relevant for the possible involvement of NRG-1/ErbB4 signaling in psychiatric disorders because (1) most PV interneurons in the prefrontal cortex (PFC) and many in the hippocampus coexpress ErbB4 (Fisahn et al., 2009; Fazzari et al., 2010; Neddens and Buonanno, 2010); (2) they are involved in gamma oscillations that are regulated by NRG-1/ErbB4 signaling and 
abnormal in schizophrenia (Kwon et al., 1999; Wilson et al., 2008; Fisahn et al., 2009); and (3) their number is reduced in the hippocampus of ErbB4 mutant mice (Neddens and Buonanno, 2010), consistent with the reduced number of PV-expressing neurons in the PFC of individuals with schizophrenia (for review, see Lewis et al., 2005). However, while ErbB4 expression in the neocortex and hippocampus appears tightly correlated with interneurons, outside the cerebral cortex, ErbB4 is expressed in other neuron types as well (Steiner et al., 1999; Gerecke et al., 2001; Fox and Kornblum, 2005).

Here we analyzed LTP and LTP reversal at hippocampal $\mathrm{SC} \rightarrow \mathrm{CA} 1$ synapses in ErbB4 $4^{-1-}, \mathrm{PV}$-Cre;ErbB4, and NRG-1 hypomorphic mice. We also compared $E r b B 4^{-1-}$ and $P V$-Cre; ErbB4 mice in a battery of behavioral tests pertinent to schizophrenia and anxiety/fear. Our results unequivocally establish the requirement of ErbB4 signaling in PV interneurons for mediating NRG's effects on synaptic plasticity, and suggest that while ErbB4 activity in PV interneurons is important for behaviors associated with exploratory activity and sensorimotor gating, NRG/ErbB4 effects on other neural populations contribute to the regulation of anxiety and fear-related behaviors.

\section{Materials and Methods}

\section{Animals}

Full and conditional Erbb4 knock-out alleles have been described previously (Gassmann et al., 1995; Golub et al., 2004). Both ErbB4 alleles target the second coding exon, removal of which destabilizes RNA and leads to the complete loss of detectable ErbB4 protein by Western blotting and immunofluorescence histology (Vullhorst et al., 2009). Full ErbB4 mutant mice were rescued from embryonic lethality by transgenic ErbB4 overexpression in the heart (ErbB4 ${ }^{M H C-E r b B 4}$ ) (Tidcombe et al., 2003). ErbB4 ${ }^{M H C-E r b B 4}$ mice were backcrossed to C57BL/6J mice for $>15$ generations. In our facility, ErbB4 ${ }^{l o x}$ mice were backcrossed for three generations to $\mathrm{C} 57 \mathrm{BL} / 6 \mathrm{~J}$ and then maintained by inbreeding. NRG-1 hypomorphic mice harbored a targeted deletion in the EGF domain $\left(N R G 1^{\Delta E G F+/-}\right)$, and were backcrossed to C57BL/6 J mice for $>15$ gen-

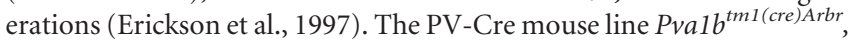
expressing Cre recombinase from the $P v a 1 b$ locus by insertion of the gene into its $3^{\prime}$ untranslated region, was obtained from The Jackson Laboratory (Hippenmeyer et al., 2005). PV-Cre mice were on a mixed $129 \times \mathrm{C} 57 \mathrm{BL} / 6 \mathrm{~J}$ background, backcrossed in our facility for two generations to $\mathrm{C} 57 \mathrm{BL} / 6 \mathrm{~J}$ and maintained as inbreds from then on. ErbB4-2ACre-ERT2 mice were provided by Dr. Hongkui Zeng (Allen Institute for Brain Science, Seattle, WA), and mice expressing tdTomato from the Rosa26 locus (Ai14) were obtained from The Jackson Laboratory (Madisen et al., 2010). For more details on the generation and expression properties of ErbB4-Cre-ERT2 mice, please go to http://transgenicmouse. alleninstitute.org. Adult ErbB4-2A-CreERT2 $\times$ Ai14 mice were injected intraperitoneally for 5 consecutive days with $1 \mathrm{mg}$ of tamoxifen (Sigma). All mice were maintained under a 12/12 h light/dark cycle and received food ad libitum. Animal procedures were reviewed and approved by the NIH Animal Care and Use Committee.

\section{Reagents}

The NRG- $1 \beta_{1}$ peptide (R\&D Systems) encompasses the EGF-like domain between amino acids 176-246, which is necessary and sufficient to activate the ErbB signaling pathway (Buonanno and Fischbach, 2001). The NRG- $1 \beta_{1}$ peptide was used because, in contrast to the entire extracellular domain, it penetrates the tissue and effectively activates ErbB receptors, as previously demonstrated (Kwon et al., 2005). PD158780 was from Calbiochem and was reconstituted in DMSO at a stock concentration of $10 \mathrm{~mm}$. Mouse monoclonal anti-parvalbumin antibody (clone PARV-19) was from Sigma. Rabbit monoclonal antibody mAB10 against ErbB4 has been described previously (Vullhorst et al., 2009). A mouse monoclonal antibody against clathrin heavy chain (clone TD.1) was from Santa Cruz Biotechnology.

\section{Protein extraction and Western blotting}

Whole tissue lysates were generated from $P V-C r e ; E r b B 4^{\mathrm{f} / \mathrm{f}}$ and $E r b B 4^{\mathrm{f} / \mathrm{f}}$ mice by sonication in $8 \mathrm{M}$ urea/1\% SDS. Proteins were reduced with $5 \mathrm{~mm}$ tributylphosphine (Sigma) and alkylated with $15 \mathrm{~mm}$ iodoacetamide (Sigma). Sixty micrograms of protein were size-fractionated on $4-12 \%$ acrylamide/Tris-glycine gels (Invitrogen) and electrophoretically transferred onto nitrocellulose membranes. Excess binding capacities were blocked with $5 \%$ nonfat dry milk in Tris-buffered saline $(137 \mathrm{~mm} \mathrm{NaCl}$, $3 \mathrm{~mm} \mathrm{KCl}, 25$ mм Tris-HCl, pH 7.4) containing 0.1\% Tween 20 (TBS-T). Membranes were probed sequentially with anti-ErbB4 (mAB10;1 $\mu \mathrm{g}$ / $\mathrm{ml})$ and mouse monoclonal antibody against clathrin heavy chain $(0.03$ $\mu \mathrm{g} / \mathrm{ml}$ ) in $3 \%$ bovine serum albumin (BSA) in TBS-T. Antibody binding was visualized with secondary antibodies conjugated to horseradish peroxidase using enhanced chemiluminescence (GE Healthcare).

\section{Electrophysiology}

Transverse slices $(300-350 \mu \mathrm{m})$ from the dorsal hippocampus were transferred to a submerged recording chamber continuously perfused at $2 \mathrm{ml} / \mathrm{min}\left(30^{\circ} \mathrm{C}\right)$ with ACSF containing the following (in $\mathrm{mm}$ ): $125 \mathrm{NaCl}$, $26 \mathrm{NaHCO}_{3}, 2.5 \mathrm{KCl}, 1.25 \mathrm{NaH}_{2} \mathrm{PO}_{4}, 2.5 \mathrm{CaCl}_{2}, 1.3 \mathrm{MgCl}_{2}$, and 11 glucose. Whole-cell voltage-clamp recordings were performed with glass microelectrodes (6-7 M $\Omega$ ) filled with internal solution (in mM: 130 Csmethanesulfonate, 10 HEPES, 0.5 EGTA, 4 Mg-ATP, 0.3 Na-GTP, 5 QX-314, $8 \mathrm{NaCl}, 10$ phosphocreatine, pH 7.2 adjusted with $\mathrm{CsOH}$ ). Schaffer collateral/commissural fibers were stimulated at $0.05 \mathrm{~Hz}(0.1$ $\mathrm{ms}, 20-40 \mu \mathrm{A})$ using a borosilicate two barrel filled with oxygenated ACSF or concentric bipolar stimulating electrode. Baseline EPSCs were set to $40-50 \%$ of maximum responses and recorded for at least $10 \mathrm{~min}$ after obtaining a stable baseline. Of note, stimulus intensities were not significantly different between genotypes. For the induction of LTP, a general pairing protocol was used, composed of 100 pulses at $2 \mathrm{~Hz}$ and a holding potential of $-10-0 \mathrm{mV}$, as previously described (Kim and Lisman, 1999; Kwon et al., 2008). Slices showing < 130\% LTP were excluded from analyses. Depotentiation was elicited by TPS ( $5 \mathrm{~Hz}, 1 \mathrm{~min})$, as described by Stäubli and Chun (1996). Picrotoxin (100 $\mu \mathrm{M})$ was included in some experiments. Recorded data were filtered at $3 \mathrm{kHz}$, sampled at 10 $\mathrm{kHz}$ using pClamp, and analyzed with Clampfit (Molecular Devices). Results are presented as mean \pm SEM and analyzed for statistical significance using the Wilcoxon signed-rank test.

\section{Immunofluorescence histology}

Mice were transcardially perfused with $4 \%$ PFA in $0.1 \mathrm{M} \mathrm{PBS,} \mathrm{pH} \mathrm{7.4.}$ Brains were postfixed overnight in the same fixative and $50 \mu \mathrm{m}$ sections were cut on a vibratome and saved for up to 3 weeks in $0.1 \mathrm{M}$ PBS with sodium azide at $+4^{\circ} \mathrm{C}$. Sections were blocked in $20 \%$ normal goat serum (NGS), $1 \%$ BSA, $0.25 \%$ Triton X-100 in $0.1 \mathrm{~m}$ PBS for $1 \mathrm{~h}$ at room temperature (RT) and incubated with anti-PV primary antibody (1: $6000)$ and/or rabbit monoclonal antibody mAB10 against ErbB4 $(1 \mu \mathrm{g} /$ $\mathrm{ml}$ ) in $0.1 \mathrm{M}$ PBS with $2 \% \mathrm{NGS}$ and $0.25 \%$ Triton X-100 (dilution buffer) for $24 \mathrm{~h}$ at $+4^{\circ} \mathrm{C}$ with gentle rocking. Slices were washed in $0.1 \mathrm{M}$ PBS with $0.25 \%$ Triton X-100 for at least 30 min before incubation with goat-antimouse Alexa 647 and/or anti-rabbit Alexa 594 secondary antibodies (Invitrogen) for $90 \mathrm{~min}$ at RT in dilution buffer. After extensive washes in PBS with $0.25 \%$ Triton X-100, sections were mounted on gelatin-coated slides, dried, and mounted in Mowiol-DABCO. Fluorescence was analyzed on a Zeiss 510 Meta confocal microscope (Zeiss Microimaging) at $20 \times$ and $40 \times$ magnification. Images were adjusted for overall brightness and contrast in Adobe Photoshop (Adobe Systems).

\section{Behavioral testing battery}

Cohorts. Only male mice were used for behavioral testing. Heterozygous $E r b B 4^{M H C-E r b B 4}$ breeders were used to establish the full ErbB4 knock-out $\left(E r b B 4^{-1-}\right)$ cohort and its respective wild-type littermate control group. For the conditionally ablated ErbB4 mutant mice, the PV-Cre driver line $P v a 1 b^{t m 1(c r e) A r b r}$ was crossed with mice harboring a floxed Erbb4 allele to obtain both $P V-C r e ; E r b B 4^{\mathrm{f} / \mathrm{f}}$ and $P V-C r e ; E r b B 4^{\mathrm{f} /-}$ mutant mice. The respective control groups were $E r b B 4^{f / f}$ and $E r b B 4^{f /-}$ without PV-Cre. Data were not different between ErbB $4^{f / f}$ and $E r b B 4^{f /-}$ mice, indicating that knocking out one allele of ErbB4 does not affect any behavioral parameters investigated in this work. Since there was no difference in the 
behavioral outcomes between the two control groups, the PV-Cre; $\mathrm{ErbB}_{4}^{\mathrm{flf}}$, and $\mathrm{PV}-\mathrm{Cre} ; \mathrm{ErbB} 4^{\mathrm{fl}-}$ cohorts were pooled and referred to as $P V$-Cre;ErbB4. Cohort size range was between 7 and 17, depending on test and genotype. Age range was between 3 and 6 months at the time of testing. Before testing, groups were assessed for general health, reflexes, and sensory and neurological functions. Cohorts were subjected to multiple behavioral tests in the following order: open field, elevated plus maze, prepulse inhibition (PPI) of acoustic startle, and fear conditioning. A second cohort of ErbB $4^{-1-}$ mice and control littermates was used for the resident intruder and saccharin preference tests.

Open field test. Locomotor activity was measured in a $35 \times 35 \mathrm{~cm}$ open field arena. Mice were placed in one corner of the arena and movements were recorded for 30 min with TopScan Suite of CleverSystems (CleverSys). The open field chamber was wiped between trials with a $70 \%$ alcohol solution.

Prepulse inhibition of the startle response. The SR-Lab Startle Response System (San Diego Instruments) was used to measure PPI. Mice were placed in a clear Plexiglas holding cylinder and, after 5 min acclimation, presented with random trials of startle ( $40 \mathrm{~ms}$ at an intensity of $120 \mathrm{~dB}$ ), prepulse + startle (20 ms of 3, 6, 12, and $17 \mathrm{~dB}$ above background noise followed, $100 \mathrm{~ms}$ later, by $40 \mathrm{~ms}$ at an intensity of $120 \mathrm{~dB}$ ) and nonstartling-stimulus (NSS). A $65 \mathrm{~dB}$ background sound was presented throughout the session. Intertrial intervals averaged 15 s (range: 5-20 s). Percentage PPI was calculated as [(startle response - NSS $)-($ prepulse + startle response - NSS)/(startle response - NSS) $]^{\star} 100$.

Elevated plus maze. A Plexiglas plus-shaped maze containing two dark enclosed arms and two open lit arms elevated $50 \mathrm{~cm}$ above ground was used to examine anxiety-related behaviors. The arms were $30 \times 5 \mathrm{~cm}$ with a $5 \times 5 \mathrm{~cm}$ center area, and the walls of the closed arms were $20 \mathrm{~cm}$ high. Trials were started by placing mice in the center of the maze. Mice were tracked for 5 min with a video camera, and then returned to their home cage. The plus maze was wiped clean between trials with a $70 \%$ alcohol solution. Time spent in the maze and frequency of visits to different zones of the maze was scored using Any Maze program (Stoelting).

Contextual and cued fear conditioning. Mice were trained and tested for fear conditioning using the San Diego Instruments Freeze Monitor. Freezing, defined as the lack of all movement other than respiration, was used as the measure of conditioned fear. Freezing was scored using the Freeze Detector System (San Diego Instruments), an automatic freezing scoring program. During training, mice were placed in the chamber and exposed to two conditioned (CS; $85 \mathrm{~dB}$ white noise, $30 \mathrm{~s}$ ) and unconditioned (US; $0.5 \mathrm{~mA}$ foot shock, $2.0 \mathrm{~s}$ ) stimulus. The CS-US stimuli were paired and separated by a $120 \mathrm{~s}$ intertrial interval. Following the last CS-US stimulus, the training session ended with a 3 min period during which freezing behavior was recorded. Contextual fear conditioning testing was performed $24 \mathrm{~h}$ after training. Mice were returned to the training chambers and freezing was scored for $5 \mathrm{~min}$. Twenty-four hours later, mice were placed in an altered context to test for generalized freezing and for cued fear conditioning. For generalized freezing, freezing behavior was scored for $2 \mathrm{~min}$ before the CS and for cued fear conditioning $3 \mathrm{~min}$ after the CS.

Resident intruder test. ErbB4 mutants and their WT control cohorts were single-housed 1 week before testing. A C57BL/6J male mouse was introduced into the home cage of the tested mouse. Their activities were videotaped for $10 \mathrm{~min}$ and scored for time spent on olfactory investigations (sniffing), and for the number of side approaches, tail rattlings, and attack bitings.

Saccharin preference test. Hedonic-like behavior was measured using the saccharin preference test. Mice were single-housed for 1 week and then tested for their preference for saccharin in their home cage. Mice were given access for $2 \mathrm{~d}$ to two 2 drinking bottles containing tap water. On day 3 , one of the water bottles was replaced with a bottle containing $0.01 \%$ saccharin solution, and the consumption of water and saccharin was measured for 2 consecutive days. The position of the bottles was changed daily to prevent side preference.

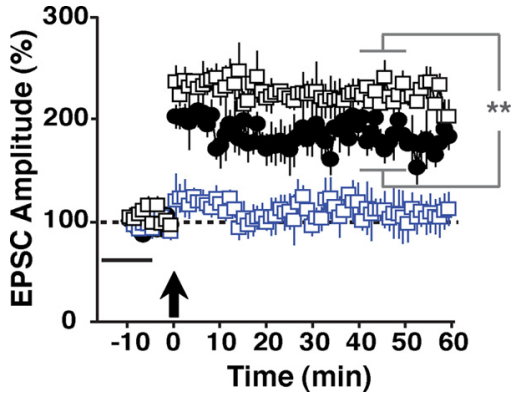

Figure 1. Effects of acute ErbB receptor activation on LTP induction at $S C \rightarrow$ CA1 synapses in WT mice. Synaptic responses were measured in whole-cell voltage-clamp mode beginning 10 min before and continuing for 60 min following LTP induction by pairing (arrow). EPSC amplitudes are relative to baseline (set as 100\%; dotted line). Perfusion with $1 \mathrm{~nm}$ NRG- $1 \beta$ for 10 min before LTP induction ( -15 min to -5 min relative to pairing; black bar) effectively inhibited LTP induction (blue squares). Following pretreatment with $10 \mu \mathrm{m}$ PD158780, NRG- $1 \beta$ no longer inhibited LTP induction (black squares). Rather, EPSC amplitudes exhibited a small but significant increase compared with normal controls (filled circles). $N=5$ (normal control), 6 (NRG-1 $\beta$ ), 5 (NRG-1 $\beta+$ PD158780). ${ }^{* *} p<0.01$.

\section{Results}

NRG-1 $\beta$ inhibits LTP induction elicited by a pairing protocol LTP can be broadly separated into induction and expression phases. At SC $\rightarrow$ CA1 glutamatergic synapses, LTP induction depends on NMDA receptor activation and expression manifests as an increase in synaptic AMPA receptor currents. We previously demonstrated that a recombinant protein encompassing the EGF domain of NRG- $1 \beta_{1}$ (hereafter referred to as NRG- $1 \beta$ ), added 20 min after LTP induction, reverses expression of LTP elicited by theta-burst stimulation or pairing by reducing AMPAR currents to preinduction levels (Kwon et al., 2005, 2008). To analyze the effects of NRG- $1 \beta$ on LTP induction using a pairing protocol, we perfused hippocampal slices with $1 \mathrm{nM}$ NRG-1 $\beta 15$ min before pairing for a total of $10 \mathrm{~min}$. Of note, NRG- $1 \beta$ had no effect on baseline EPSCs in the absence of LTP-inducing stimuli, as shown previously (Kwon et al., 2005). As illustrated in Figure 1, pairing failed to induce LTP in NRG- $1 \beta$ pretreated slices $(-10-0$ min: $95 \pm 14 \%$; $40-50 \mathrm{~min}: 105 \pm 19 \%$ ), while untreated control slices exhibited robust LTP $(188 \pm 15 \%$; $p<0.01$ for the comparison between controls and NRG-1 $\beta$ at $40-50$ min after pairing). NRG- $1 \beta$ did not block LTP induction when slices were pretreated with the pan-ErbB receptor kinase inhibitor PD158780 (10 $\mu \mathrm{M})$. Moreover, compared with untreated controls, a small but significant enhancement of LTP was observed, suggesting that inhibition of endogenous NRG/ErbB signaling by PD158780 augments LTP (229 $\pm 9 \%$ vs $188 \pm 15 \% ; p<0.01)$.

LTP is enhanced in full and PV interneuron-restricted ErbB4 mutant as well as NRG-1 hypomorphic mice

ErbB4 is the major neuregulin receptor in CNS neurons, and pharmacological ErbB receptor blockade by PD158780 blocks LTP reversal by NRG- $1 \beta$ and neural activity (Kwon et al., 2005). However, direct genetic evidence implicating ErbB4 in LTP reversal at $\mathrm{SC} \rightarrow \mathrm{CA} 1$ synapses has been lacking. We therefore began by comparing LTP in slices from wild-type and $E r b B 4^{M H C-}$ ErbB4 mice harboring a mutant Erbb4 gene in all cells. These mice, hereafter referred to as ErbB4 $4^{-1-}$, are rescued from embryonic lethality by transgenic expression of ErbB4 in the heart (Tidcombe et al., 2003). As shown in Figure 2A, LTP was significantly enhanced in mutants compared with control wild-types (ErbB4 ${ }^{-1-}: 260 \pm 17 \%$ vs WT: $\left.181 \pm 12 \%, p<0.001\right)$, consistent with the acute effects of ErbB receptor blockade by 
A

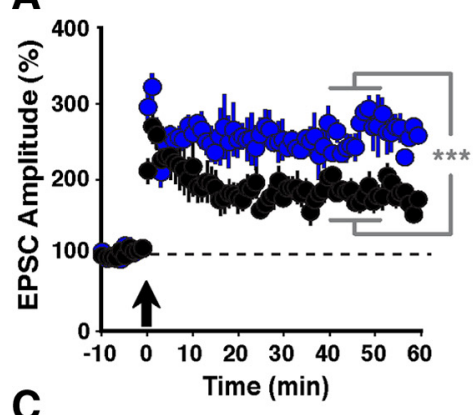

C

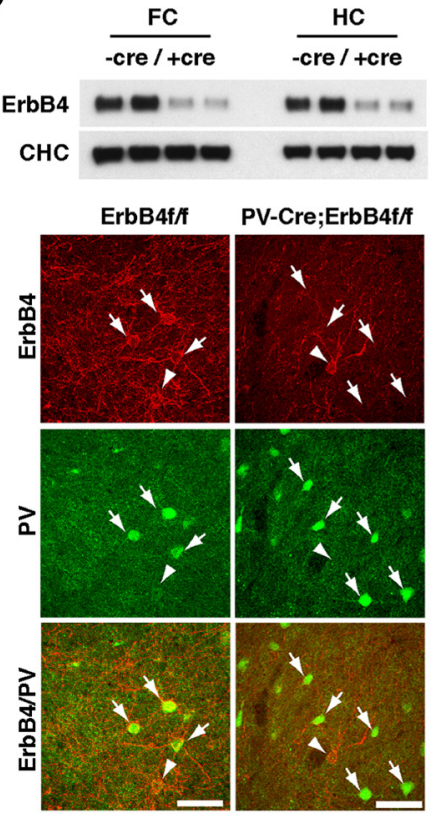

B

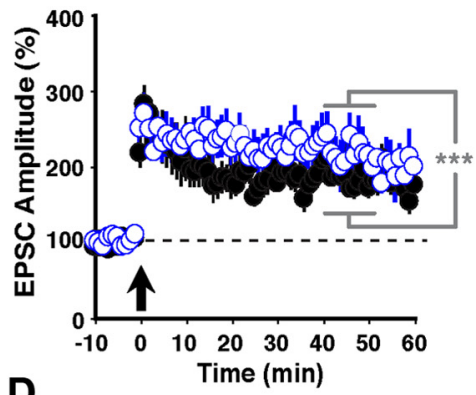

$D_{40}$
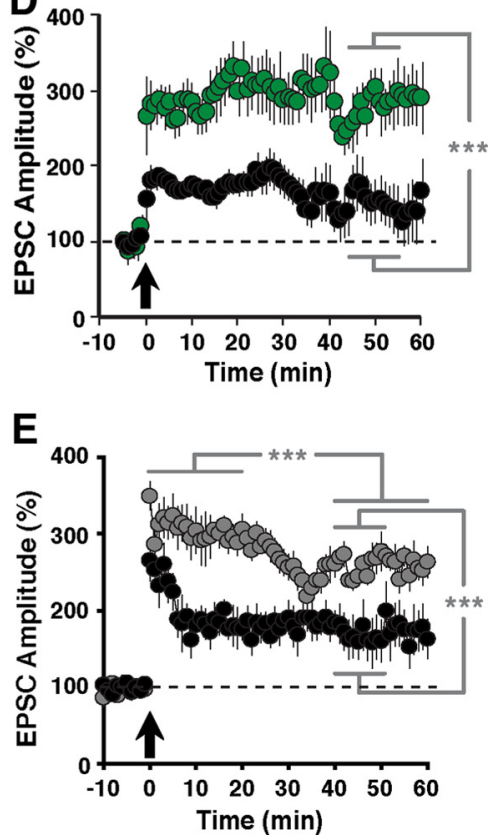

Figure 2. LTP in ErbB4 and NRG-1 mutant mice. EPSCs were measured as described in Figure 1. Compared with normal controls $\left(\boldsymbol{A}, \boldsymbol{B}, \boldsymbol{D}, \boldsymbol{E}\right.$; black circles), hippocampal slices from ErbB4 ${ }^{-1-}\left(\boldsymbol{A}\right.$; solid blue circles) and ErbB4 ${ }^{+/-}$mice (B; open blue circles) exhibited enhanced LTP throughout the entire recording period following pairing. $N=6(\mathrm{WT}), 8\left(E r b B 4^{-1-}\right), 4\left(E r b B 4^{-1+}\right) . C$, Top, Western blot analysis of ErbB4 protein levels in whole tissue lysates from the frontal cortex (FC) and hippocampus (HC) of control ErbB4 ${ }^{\mathrm{f} / \mathrm{f}}$ (- cre) and PV-Cre;ErbB4 ( + cre) mice. Representative results from two animals are shown for each genotype. Clathrin heavy chain (CHC) is included as a loading control. Bottom, Coimmunofluorescence of ErbB4 (red) and PV (green) in the frontal cortex of $P V$-Cre;ErbB4 mice. In ErbB4 ${ }^{\mathrm{f} / \mathrm{f}}$ controls, numerous PV $(+)$ cells coexpress ErbB4 (arrows). In contrast, ErbB4 is not detected in PV $(+)$ cells from PV-Cre;ErbB4 mice. Arrowheads mark ErbB4(+) cells that are negative for PV. Scale bars, $100 \mu \mathrm{m} . \boldsymbol{D}$, Selective ablation of ErbB4 in PV interneurons (green) results in higher LTP, mimicking the effects of complete loss of ErbB4. $N=$ 8 (ErbB4 ${ }^{\mathrm{f} / \mathrm{f}}$ controls) and 6 (PV-Cre;ErbB4; green). $E$, LTP was also increased in slices from NRG-1 ${ }^{+1-}$ mice (gray), although it runs down somewhat 25 min postinduction. $N=5$ (WT), $8\left(N R G-1^{+/-}\right)$. ${ }^{* * *} p<0.001$.

PD158780 on LTP in wild-type mice. These findings support the notion that NRG/ErbB4 signaling in the hippocampus serves as a counterbalance to the effects of potentiating stimuli. We also measured LTP in ErbB4 heterozygous mice and found that it was

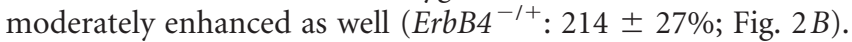
The magnitude of LTP was between those observed in wild-type and ErbB4 ${ }^{-1-}$ mice, and mean EPSC amplitudes between 40 and $50 \mathrm{~min}$ after pairing were significantly different from both $(p<$ 0.001 for both comparisons), indicating that ErbB4 dosedependently antagonizes LTP.

We next investigated the specific role of ErbB4 signaling in PV interneurons for hippocampal plasticity. PV-Cre;ErbB4 mice, obtained by crossing mice harboring a conditional ErbB4 allele with mice expressing Cre recombinase from the PV locus, show strongly reduced ErbB4 protein levels in extracts from the frontal cortex and hippocampus (Fig. 2C, top). This is consistent with the extensive coexpression of ErbB4 in PV interneurons in both areas (Neddens and Buonanno, 2010). Residual signals observed in extracts from $\mathrm{PV}$-Cre;ErbB4 mice likely represent ErbB4 expression by other GABAergic interneurons that also coexpress ErbB4. To ascertain the faithfulness of PVCre-mediated ErbB4 ablation, we colabeled sections from the frontal cortex where virtually all PV interneurons coexpress ErbB4 (Neddens et al., 2011). As shown in Figure $2 C$ (bottom), while we frequently observed ErbB4-IR in PV interneurons from control sections from $\operatorname{ErbB} 4^{\mathrm{f} / \mathrm{f}}$ mice, we were unable to find ErbB4-IR in PV interneurons from PV-Cre;ErbB4 mice. Occasional ErbB4-IR cells were immunonegative for $\mathrm{PV}$ and likely represented other types of GABAergic interneurons. Similar results were obtained in the hippocampus (data not shown). We then proceeded to measure LTP in PV-Cre; ErbB4 mice. Consistent with the notion that ErbB4 signaling in PV interneurons plays an important role in mediating the effects of NRG-1 on hippocampal plasticity, we found that normalized mean EPSC amplitudes were significantly increased in $P V$ Cre;ErbB4 mice compared with their control ErbB4 $4^{\mathrm{f} / \mathrm{f}}$ littermates ( $P V$-Cre;ErbB4: $322 \pm 43 \%$ vs $\operatorname{ErbB}^{\mathrm{f} / \mathrm{f}}: 157 \pm 13 \% ; p<$ $0.001)$.

The acute effects of NRG-1 on LTP have been studied by perfusing hippocampal slices with exogenous NRG- $1 \beta$ peptide (Fig. 1). To investigate the role of endogenous NRG-1, which is expressed in CA3 pyramidal neurons (Law et al., 2004; Longart et al., 2004), we compared LTP between wild-type mice and heterozygous NRG-1 mutant mice with targeted deletions of exons encoding the EGF-like domain; NRG-1-null mice die at E9.5 and could therefore not be used. As in the case of ErbB4 mutant and hypomorphic mice, NRG-1 heterozygous mice exhibited enhanced LTP (NRG-1 $1^{+/-}: 258 \pm 14 \%$ vs WT: $166 \pm 28 \%, p<0.001$; Fig. $2 E$ ). However, we noticed a somewhat different time course following LTP induction, with an apparent extended period of strongly enhanced LTP immediately after pairing, followed by a phase marked by decreasing LTP levels and eventual stabilization at intermediate levels that were remarkably similar to LTP in ErbB4-null mice (mean relative EPSC amplitudes: $306 \pm 23 \%$ at $0-20 \mathrm{~min}$ vs $259 \pm 16 \%$ at $40-60 \mathrm{~min}, p<$ 0.001 ). While these findings might suggest additional effects of NRG-1 hemizygosity on synaptic plasticity at SC $\rightarrow$ CA1 synapses, they are nevertheless consistent with the notion that genetic perturbations of both the ligand and the receptor result in similar outcomes and support the idea that endogenous NRG-1/ ErbB4 signaling acts as a counterbalance to LTP-promoting processes.

LTP reversal by NRG-1 $\beta$ or TPS is absent in $E r b B 4^{-/-}$mice In wild-type controls, $1 \mathrm{~nm} \mathrm{NRG-1} \beta$, perfused 20 min after pairing for a total of $10 \mathrm{~min}$, rapidly reverted LTP back to baseline 
levels (Fig. 3A). By contrast, slices from ErbB4-null mice were resistant to the acute effects of exogenously added NRG-1 $\beta\left(\right.$ ErbB $^{-1-}: 220 \pm 16 \%$ vs WT: $104 \pm 18 \%, p<0.001)$, demonstrating the critical requirement of ErbB4 for NRG- $1 \beta$-mediated LTP reversal. LTP can also be reversed by TPS ( $5 \mathrm{~Hz}, 1 \mathrm{~min})$ if delivered shortly after LTP induction. TPS are modeled after normal hippocampal activity patterns observed during exploratory activity, and therefore represent a possible endogenous pathway for LTP reversal (Stäubli and Chun, 1996). We have previously shown that TPSmediated LTP reversal is absent when slices are pretreated with the ErbB receptor inhibitor PD158780 (Kwon et al., 2005), implicating NRG/ErbB signaling in mediating the effects of TPS on early phase hippocampal LTP. As shown in Figure $3 B$, application of TPS 5 min after LTP induction by pairing is ineffective in slices from $\operatorname{ErbB} 4^{-1-}$ mice whereas they completely reverse LTP in slices from wildtype mice $\left(\mathrm{ErbB}^{-1-}: 199 \pm 15 \%\right.$ vs WT: $107 \pm 15 \%$ of baseline, $40-50$ min after LTP induction). Likewise, TPS were also without effect in $P V$-Cre; ErbB4 mice $(P V$ Cre;ErbB4: $261 \pm 3 \%$ vs ErbB4 $4^{\mathrm{f} / \mathrm{f}}: 121 \pm$ $3 \%$; $p<0.002$; Fig. 3C). Together, these data firmly establish ErbB4 as a critical mediator of the inhibitory effects of NRG-1 and TPS on earlyphase LTP, and furthermore reveal PV interneurons as the primary locus of ErbB4 signaling underlying LTP reversal.

It is reasonable to assume that TPS might trigger LTP reversal by somehow promoting the release of endogenous NRG to activate ErbB4. We reasoned, therefore, that TPS in NRG-1 heterozygous mice might be less effective than in WT mice. Consistent with this idea, Figure $3 C$ shows that unlike in WT slices, EPSC amplitudes in slices from NRG-1 heterozygous mice remained elevated after TPS and only slowly ran down (10-20 min: $164 \pm$ $46 \%$ vs $30-40 \mathrm{~min}: 137 \pm 41 \%$; $p<0.01)$ to stabilize at levels that continued to be moderately potentiated (average EPSC amplitudes 30-60 min after pairing: NRG-1 $1^{+/-}: 134 \pm 40 \%$ vs WT: $111 \pm 21 \% ; p<0.001)$. These data are consistent with the idea that reduced levels of NRG-1 in NRG-1 ${ }^{+/-}$mice are only partly effective to stimulate ErbB4 signaling in response to TPS.

\section{Behavioral analysis of full and}

\section{PV-interneuron selective ErbB4 mutant mice}

A recent study reported some behavioral abnormalities in mice in which the Erbb4 gene was conditionally ablated using Cre expressed under the control of the PV promoter (Wen et al., 2010). Since a comprehensive behavioral analysis has not been performed for mice lacking ErbB4 in all neurons, we sought to compare cohorts of ErbB4 $4^{-1-}$ and PV-Cre;ErbB4 mice with their respective wild-type littermate controls in a battery of tests designed to investigate rodent behaviors potentially pertinent for behavioral abnormalities found in individuals with schizophrenia and other psychiatric disorders. The battery of tests performed on these cohorts included open field, PPI of acoustic startle, elevated plus maze, fear conditioning, as well as saccharin preference and resident intruder tests. Because the ErbB $4^{-1-}$ cohort exhibited no alterations in the saccharin preference test (a paradigm used for the assessment of hedonic behavior) or the resident intruder test for aggressive behavior, we did not subject the PV-Cre;ErbB4 cohort to these tests.

\section{Open field test}

Spontaneous locomotor activity in response to novelty is widely used to model positive symptoms of schizophrenia. In the open field test, both ErbB4 ${ }^{-1-}$ and PV-Cre;ErbB4 cohorts exhibited significantly more locomotor activity than their respective normal littermate control groups (Fig. 4). This hyperactivity was apparent at all times during the 30 min observations. Full ErbB4 knock-out mice traveled a total distance of $6900 \pm 550 \mathrm{~cm}$, compared with $4600 \pm 460 \mathrm{~cm}$ in the control group $(n=17$ for both groups; $p<0.05$, Student's $t$ test). Similarly, $P V$-Cre;ErbB4 mice traveled a total distance of $6000 \pm 480 \mathrm{~cm}$ compared with their littermate control group that traveled $4500 \pm 420 \mathrm{~cm}(p<0.05$, Student's $t$ test). Although the observed differences in total distance traveled between the full and PV interneuron-restricted Erbb4-null mice were suggestive of an effect of genotype, differences in strain backgrounds between these two mutants precluded a direct comparison. Notwithstanding, the finding that both strains of ErbB4 mutant mice were hyperactive strongly suggests that ErbB4 signaling in PV interneurons contributes substantially to the regulation of novelty-induced locomotor activity.

PPI of the startle response

PPI is a widely used measure of sensorimotor gating in rodents and humans (Geyer, 2008), and deficits in this task have been 
A

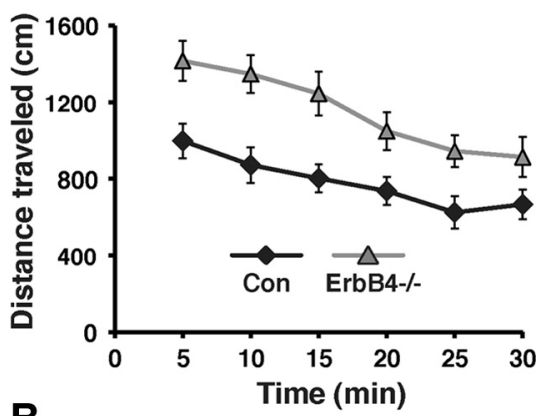

B

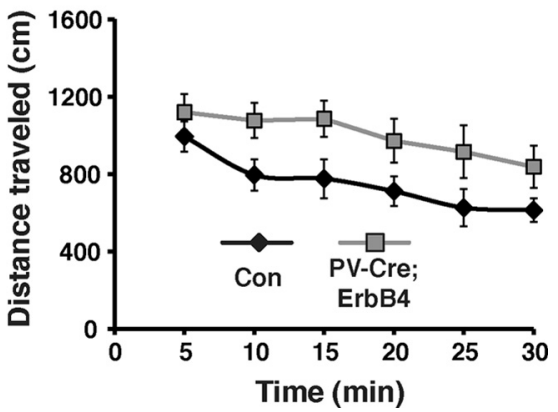

Figure 4. $E r b B 4^{-1-}$ and $P V$-Cre;ErbB4 mice are hyperactive. $\boldsymbol{A}, \boldsymbol{B}$, Time course of spontaneous locomotor activity during the first $30 \mathrm{~min}$ following placement in the novel environment for ErbB4 ${ }^{-1-}$ (gray triangles) and its littermate control group (Con, black diamonds) $(\boldsymbol{A})$ and for $P V$-Cre;ErbB4 mice (gray squares) and its respective littermate controls (Con, black diamonds) (B). Data points represent 5 min bins of locomotor activity. $N=17$ for ErbB4 ${ }^{-1-}$ and its control group; $N=8$ for PV-Cre;ErbB4 and 11 for its control group.

reproducibly found in individuals with schizophrenia (Braff, 2010). Figure 5 shows that, like in the open field test, both ErbB4 mutants exhibited deficits in PPI. Two-way ANOVA with repeated measurements detected significant effects of genotype $(p<0.01)$ and genotype $\times$ prepulse sound level $(p<0.05)$. Post hoc analysis revealed that reductions in PPI levels were more pronounced at lower prepulse sound levels ( $68 \mathrm{~dB}: 6 \pm 2 \%$ and $23 \pm 5 \%$ for $E r b B 4^{-l-}$ vs controls, $p<0.05 ; 15 \pm 5 \%$ and $32 \pm$ $5 \%$ for $P V$-Cre;ErbB4 vs controls; $p<0.01)$ than at higher prepulse sound levels ( $77 \mathrm{~dB}: 58 \pm 8 \%$ and $80 \pm 2 \%$ for $E r b B 4^{-1-}$ vs controls, $p<0.05 ; 65 \pm 7 \%$ vs $86 \pm 2 \%$ for $P V$-Cre;ErbB4 vs controls; $p<0.05)$. At $82 \mathrm{~dB}$, PPI was not significantly different between both ErbB4 mutant strains and their respective controls ( $94 \pm 1 \%$ and $89 \pm 3 \%$ for controls vs ErbB4 ${ }^{-l-}, p=0.11 ; 89 \pm$ $1 \%$ and $81 \pm 5 \%$ for controls vs $P V$-Cre;ErbB4; $p=0.14$ ). These data indicate that PPI deficits are more pronounced at smaller differentials between the prepulse and background sound levels (68 dB: $\Delta 3 \mathrm{~dB} ; 82 \mathrm{~dB}: \Delta 17 \mathrm{~dB}$ ). Importantly, acoustic startle responses, per se, were not significantly different between mutants and their respective controls, affirming that all pertinent sensorimotor functions were unaffected (data not shown).

Elevated plus-shaped maze

To evaluate possible alterations in fear and anxiety-related behaviors in ErbB4 mutant mice, we tested their performance in the

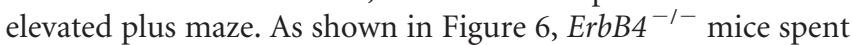
significantly more time in the open arms during the 5 min trials than their wild-type littermates (open arm: $97 \pm 20 \mathrm{~s}$ for ErbB4 $4^{-1-}$ vs $34 \pm 18 \mathrm{~s}$ for controls; closed arm: $197 \pm 17 \mathrm{~s}$ for ErbB4 ${ }^{-l-}$ vs $279 \pm 29$ s for controls; $p<0.05$ for both arms). By contrast, $\mathrm{PV}$-Cre;ErbB4 mice spent as much time in the closed
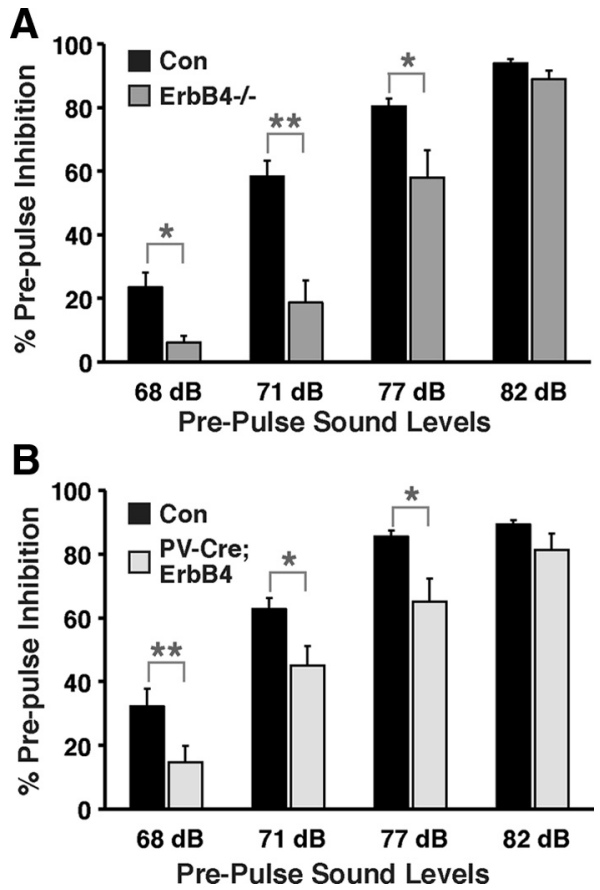

Figure 5. ErbB4 ${ }^{-1-}$ and PV-Cre;ErbB4 mice show deficits in PPI of the acoustic startle response. $\boldsymbol{A}, \boldsymbol{B}$, Percentage inhibition of the startle response as a function of increasing prepulse sound levels $(68,71,77,82 \mathrm{~dB})$ for ErbB4 ${ }^{-1-}$ and their controls (Con) $(N=$ 8 for both groups; $\boldsymbol{A})$ and for PV-Cre;ErbB4 and their controls ( $N=12$ for both groups; $\boldsymbol{B})$. A $65 \mathrm{~dB}$ background sound was presented throughout the sessions. ${ }^{*} p<0.05$; ${ }^{* *} p<0.01$.
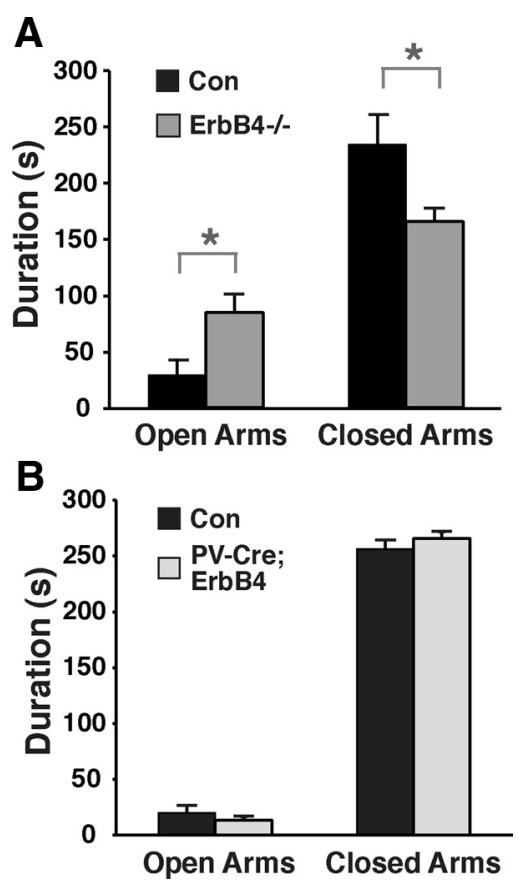

Figure 6. Reduced anxiety in ErbB4 ${ }^{-1-}$ but not $P V$-Cre,ErbB4 mice. $\boldsymbol{A}, \boldsymbol{B}$, Time spent in open and closed arms of the elevated plus maze during 5 min trials for ErbB4 ${ }^{-I-}(N=7$ for both groups; A) and for PV-Cre,ErbB4.N = 11 for controls (Con) and 8 for PV-Cre;ErbB4; B]. ${ }^{*} p<0.05$.

arms as their control littermates (open arm: $13 \pm 3 \mathrm{~s}$ for $P V$-Cre; $E r b B 4$ vs $20 \pm 7 \mathrm{~s}$ for controls, $p=0.47$; closed arm: $266 \pm 6 \mathrm{~s}$ for $P V$-Cre;ErbB4 vs $256 \pm 8$ s for controls; $p=0.4$ ). Moreover, $E r b B 4^{-1-}$ mice entered the open arms approximately twice as 
A

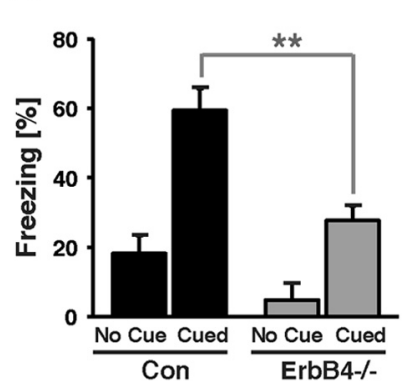

C

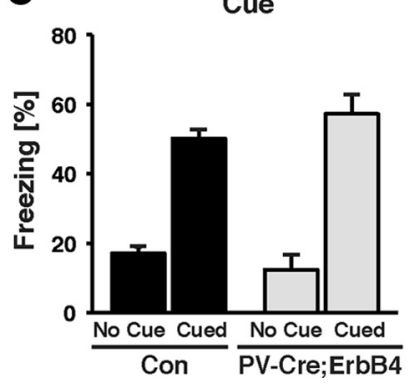

B Contextual

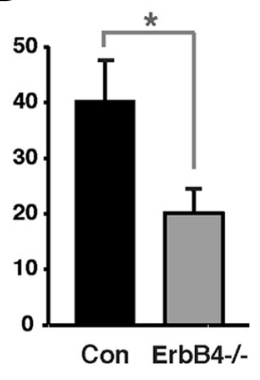

D

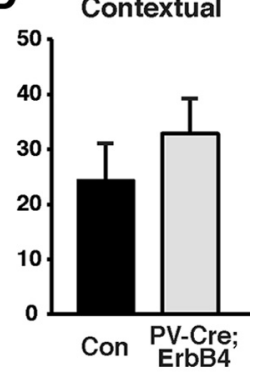

Figure 7. ErbB4 ${ }^{-1-}$ mice, but not $P V-C r e ; E r b B 4$ mice, exhibit deficits in fear conditioning. $A-D$, Freezing behavior, plotted as the fraction of time spent motionless, was recorded for $3 \mathrm{~min}$ following presentation of the $C S$ to assess cued fear conditioning $(A, C)$ and for $5 \mathrm{~min}$ following return to the training chamber to measure contextual fear conditioning $(\boldsymbol{B}, \boldsymbol{D})$. Generalized fear (no cue) was assessed for 2 min before presentation of the CS. ErbB4 ${ }^{-1-}$ mice exhibit reduced cued and contextual fear responses $(\boldsymbol{A}, \boldsymbol{B} ; N=8$ for both groups), whereas responses in $P V$ - $C r$; ErbB4 mice were not different from controls (Con) (C, $\boldsymbol{D} ; N=11$ for controls and 8 for $P V$-Cre; ErbB4). ${ }^{*} p<0.05,{ }^{* *} p<0.01$.

often as their wild-type controls (on average, 13.9 vs 6.9 visits) and also visited the closed arms approximately twice as often (18.3 vs 10.4 visits). The increased overall activity of $E r b B 4^{-1-}$ mice in the elevated plus-shaped maze, as assessed by the increase in the number of entries into either arm, is generally considered a built-in control measure for general activity, and therefore consistent with the corresponding data from the open field test. Together, these results suggest reduced anxiety in ErbB4-null mice. However, unlike in the open field and PPI tests, defective ErbB4 signaling in PV interneurons apparently does not account for the effects observed in full ErbB4 ${ }^{-1-}$ mice.

\section{Cued and contextual fear conditioning}

To more directly assess the role of ErbB4 in fear-related behaviors, and to reveal possible differences between full and PVinterneuron selective ErbB4 mutants, we tested our cohorts in cued and contextual fear conditioning. Cued fear conditioning is generally believed to be largely dependent on the amygdala, while contextual fear conditioning involves both the amygdala and the hippocampus (Phillips and LeDoux, 1992). Interestingly, before and during the two training trials, freezing levels were consistently lower for ErbB4 $4^{-1-}$ mice compared with controls (naive, $3 \%$ vs $10 \%$; first trial, $8 \%$ vs $21 \%$; second trial, $21.2 \%$ and $33.5 \%$; $F_{(2,42)}=7.04 ; p<0.05$, two-way ANOVA). However, no interaction between genotype and trial was found $\left(F_{(2,42)}=0.23\right.$; $p=0.80$, two-way ANOVA), suggesting that the difference in freezing between WT and mutant mice is not related to training, i.e., the ability of $E r b B 4^{-1-}$ mice to acquire conditioned fear. Unlike full ErbB4 mutant mice, PV-Cre;ErbB4 mice and their controls performed similarly during training. As shown in Figure

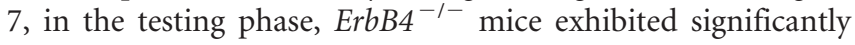

lower freezing responses when presented with the conditioned stimulus in a completely new context, as well as when returned to the training environment (cue: $59 \pm 6 \%$ for controls vs $28 \pm 4 \%$ for $E r b B 4^{-I-}, p<0.01$; context: $40 \pm 7 \%$ for controls vs $20 \pm 4 \%$ for $E r b B 4^{-1-}, p<0.05$; Student's $t$ test). In stark contrast, neither cued nor contextual fear conditioning was different between the $P V$-Cre;ErbB4 group and their controls (cue: $50 \pm 4 \%$ for controls vs $57 \pm 6 \%$ for PV-Cre;ErbB $4, p=0.31$; context: $24 \pm 7 \%$ for controls vs $33 \pm 6 \%$ for PV-Cre;ErbB4, $p=0.39$; Student's $t$ test). Together, the results from the elevated plus maze and fear conditioning tests suggest that the NRG/ErbB4 signaling pathway affects neural circuits involved in the regulation of anxiety and fear-related behaviors, but that ErbB4 effects on PV interneurons play a minor role in these processes.

\section{ErbB4 and PV expression is mostly non-overlapping in the amygdala}

To further substantiate the notion that ErbB4 deficiency in PV interneurons is unlikely to contribute to altered amygdalar function observed in full ErbB4 mutants, we analyzed expression of ErbB4 and PV in the amygdala. PV mRNA expression is generally sparse in basolateral (BLA) and basomedial (BMA) areas, two of the major amygdalar nuclei (Fig. 8) (Allen Mouse Brain Atlas, 2009). By comparison, ErbB4 mRNA signal density in the BLA is moderately higher and is extraordinarily high in the BMA. We used immunofluorescence histology to determine the extent of coexpression of PV and ErbB4. To unambiguously identify ErbB4- and PV-expressing cell bodies, we resorted to a mouse line in which tamoxifen-inducible Cre recombinase expressed from the Erbb4 locus and translated from a fusion transcript between ErbB4 and Cre drives the recombination and subsequent high-level expression of tdTomato fluorescent protein from the Rosa26 locus (Erbb4-2A-CreERT2). This mouse has been shown to faithfully report the expression pattern of ErbB4 (Madisen et al., 2010). As shown in Figure 8, the general pattern of cell bodies expressing ErbB4 mRNA and tdTomato following Cre-mediated recombination was very similar, with high densities of fluorescent cell bodies in the BMA, and a much sparser distribution in the BLA. Strikingly, the overlay between tdTomato and PV demonstrates that, while some colocalization was observed in the BLA where both ErbB4 and $\mathrm{PV}$ are sparse, virtually all tdTomato expression in the BMA was in cells immunonegative for PV. We conclude that the majority of ErbB4-expressing cells in the amygdala are not PV interneurons. This finding provides a rational basis for the observed differences in fear-related behaviors between full and PV-restricted ErbB4 mutant mice.

\section{Discussion}

The major findings of this study are as follows: (1) $E r b B 4^{-1-}$, $P V$-Cre;ErbB 4, and NRG-1 hypomorphic mice all show enhanced hippocampal LTP; (2) ErbB4 mediates the effects of NRG-1 and TPS on LTP reversal; (3) ErbB4 signaling in PV interneurons is critical to reverse LTP by neuronal stimuli; and (4) ErbB4 ${ }^{-/-}$ mice exhibit numerous behavioral deficits, some of which they share with, and others that are not reproduced by, $\mathrm{PV}$-Cre;ErbB4 mice. Our findings firmly establish NRG/ErbB4 signaling in PV interneurons as an important counterbalance to processes promoting hippocampal LTP, and as a powerful modulator of behaviors relevant to schizophrenia and other psychiatric disorders. Intriguingly, deficits in synaptic plasticity have been postulated to contribute to functional dysconnectivity in schizophrenia 

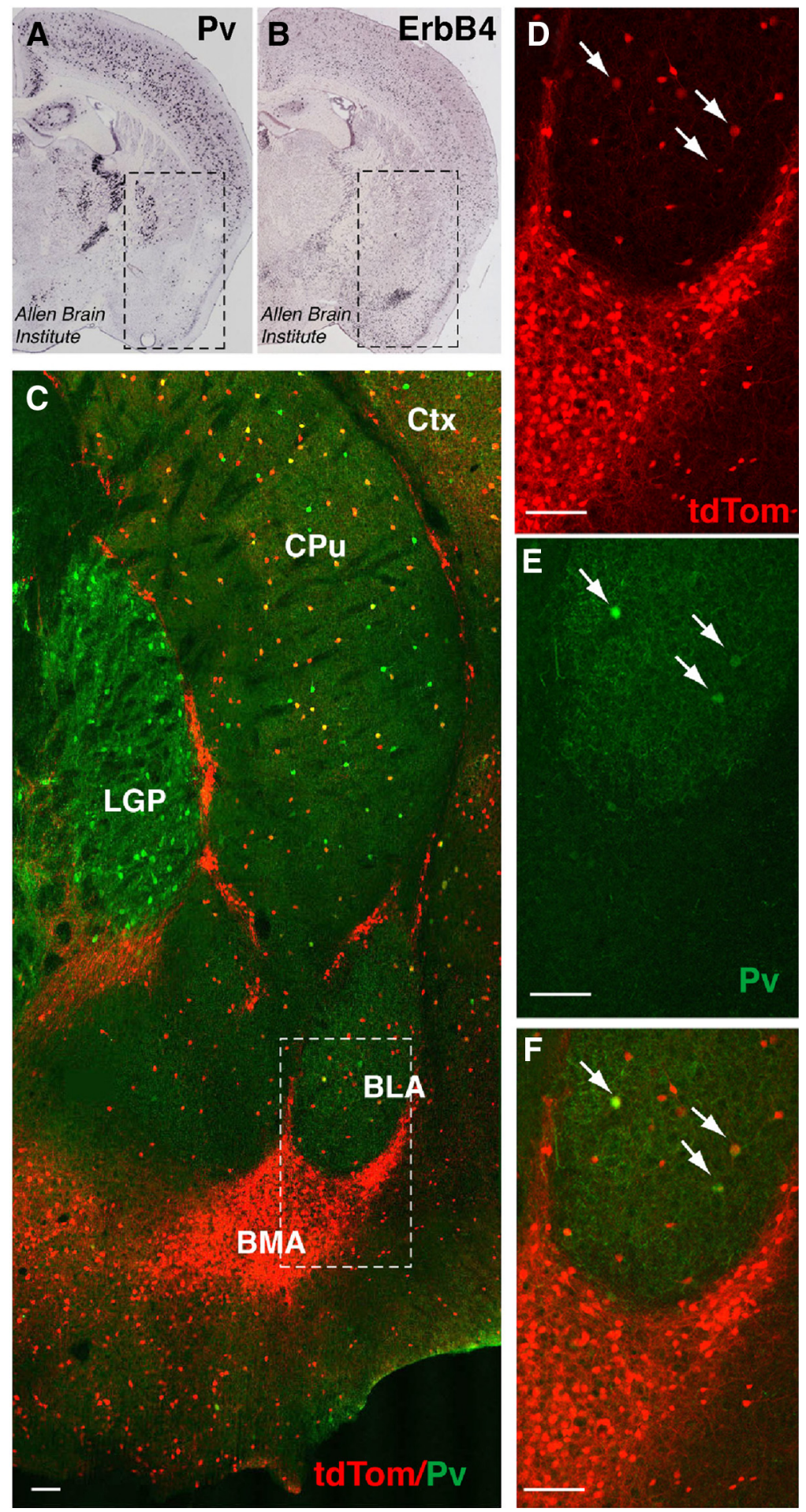

Figure 8. ErbB4 is abundantly expressed in the amygdala and shows only modest colocalization with PV.A, B, In situ hybridization of PV and ErbB4 in coronal sections of P56 mice (Allen Brain Atlas, 2009). Boxed areas correspond to the region shown in $C$ and include the amygdala (ventrally), caudate/putamen, and the lateral global pallidus (dorsally). PV mRNA signals are dense in the lateral globus pallidus (LGP), sparse in the BLA, and not detectable in the BMA. By contrast, ErbB4 mRNA signals are very dense in the BMA and more sparsely distributed in most other areas. C, Co(immuno)fluorescence micrograph image of tdTomato (tdTom; red), reporting ErbB4 expression in adult Ai14 $\times$ ErbB4-2A-CreERT2 mice, and endogenous PV (green). The boxed area is magnified in D-F. While few tdTomato-labeled cells in the BLA coexpress PV (arrows), virtually none of the large number of the ErbB4-expressing cells in the BMA and other intercalated areas coexpress PV. CPu, Caudate-putamen; Ctx, cerebral cortex; LGP, lateral globus pallidus. Scale bar, $100 \mu \mathrm{m}$.

(Stephan et al., 2006; Uhlhaas and Singer, 2010). Abnormal regulation of LTP in NRG-1 and ErbB4 mutant mice could therefore conceivably contribute to behavioral phenotypes observed by us and other groups.

\section{Hippocampal synaptic plasticity in ErbB4-null mice}

We chose to compare the involvement of ErbB4 in hippocampal LTP using ErbB4null and $P V$-Cre;ErbB4 mice to account for the intricate spatial and temporal expression pattern of ErbB4 in the rodent cortex on the one hand, and the prominent postnatal expression of ErbB4 in PV interneurons on the other hand. ErbB4 is expressed throughout development and in the adult brain (Lai and Lemke, 1991; Gerecke et al., 2001; Fox and Kornblum, 2005), and its expression pattern in the adult hippocampus indicates a complex distribution of ErbB4 expression in distinct interneuron subclasses (Yau et al., 2003; Neddens and Buonanno, 2010). During embryonic development, ErbB4 is involved in interneuron migration (Anton et al., 2004; Flames et al., 2004), and the number of GAD67- and PVimmunoreactive interneurons in the hip-

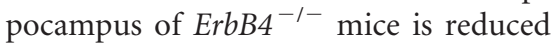
by $24 \%$ and $31 \%$, respectively (Fisahn et al., 2009; Neddens and Buonanno, 2010). However, Erbb4 ablation in PV-Cre;ErbB4 mice presumably occurs late during perinatal development ( $>$ P13), after GABAergic neuronal migration, due to the late onset of PV expression in the rodent cortex (del Río et al., 1994; Madisen et al., 2010). It is therefore unlikely that increased LTP and deficits in LTP reversal observed in both $\mathrm{ErbB}^{-1-}$ and $\mathrm{PV}$-Cre; ErbB4 mice reflect aberrant neurodevelopmental processes. This idea is also consistent with the ability of the ErbB receptor inhibitor PD158780 to acutely increase LTP levels and to block LTP reversal by TPS (Kwon et al., 2005). Notwithstanding, both NRG-1/ErbB4 signaling during development and in other interneuron types in the adult brain conceivably affect the balance of excitatory and inhibitory transmission, and could contribute to the behavioral abnormalities observed in full, but not $P V$-Cre; ErbB4, mice.

An important unresolved question remains as to the specific role of inhibitory interneurons and GABAergic transmission in mediating LTP inhibition by NRG-1/ErbB4. While electrophysiological recordings in the initial studies were performed in the presence of bicuculline (Huang et al., 2000; Kwon et al., 2005), an inhibitor of fast GABAergic transmission, recent reports differ with regards to the role of fast GABAergic transmission for LTP inhibition by NRG-1 (Chen et al., 2010; Pitcher et al., 2011). Consistent with Huang et al. (2000) and Pitcher at al. (2011), we found that $\mathrm{GABA}_{\mathrm{A}}$ receptor blockade does not affect LTP reversal by NRG-1 or TPS 
(Kwon et al., 2005). Because of the interneuron-restricted expression of ErbB4 in the hippocampus and the finding that selective ablation of Erbb4 in pyramidal neurons does not affect NRG-1mediated inhibition of LTP induction (Chen et al., 2010), the most parsimonious scenario still places the first events leading up to LTP inhibition or reversal on ErbB4-expressing PVinterneurons. Based on our previous findings that NRG-1 acutely triggers dopamine release in the dorsal hippocampus, and that LTP reversal by NRG- 1 and TPS critically depends on the activation of dopamine D4 receptors (Kwon et al., 2008), we propose that NRG/ErbB4 signaling in PV interneurons engages this dopaminergic signaling pathway to regulate synaptic plasticity; a direct effect of NRG on dopaminergic terminals cannot presently be excluded. Future studies will be necessary to work out the mechanism by which this occurs.

\section{ErbB4 and behavior}

Based on the intricate expression pattern of ErbB4 during development and in the adult brain, we decided to compare the behavioral outcomes between $\mathrm{ErbB}^{-1-}$ and $\mathrm{PV}$-Cre;ErbB4 mice. Interest in identifying the potential role of $\mathrm{PV}$-expressing interneurons in mediating NRG/ErbB4 effects on behavior stems from multiple observations, including (1) the extensive coexpression of PV and ErbB4 in the PFC and, albeit to a lesser extent, the hippocampus (Fisahn et al., 2009; Fazzari et al., 2010; Neddens and Buonanno, 2010); (2) the notion that PV interneurons are involved in gamma oscillations whose power is reduced in schizophrenia (Kwon et al., 1999; Wilson et al., 2008); and (3) the finding that the number of PV mRNA and protein-expressing cells is reduced in the PFC of individuals with schizophrenia (for review, see Lewis et al., 2005). Intriguingly, acute NRG-1/ErbB4 signaling potently augments the power of kainateinduced hippocampal gamma oscillations, while slices from ErbB $4^{-I-}$ mice exhibit reduced gamma power. Moreover, the number of $\mathrm{PV}$ interneurons is reduced by $31 \%$ in the hippocampus of ErbB4 ${ }^{-1-}$ mice (Fisahn et al., 2009).

Our study represents the first comprehensive behavioral analysis of mice lacking ErbB4 in all cells except the heart. Only one study investigated the effects of selectively ablating Erbb4 throughout the CNS by crossing floxed Erbb4 with Nestin-Cre mice (Golub et al., 2004). The authors interestingly observed that adult mutant mice were hypoactive in a novel environment. A second study, using hGFAP-Cre to ablate both Erbb2 and Erbb4 genes in the CNS, found no difference in horizontal activity, but interpretation of this finding is complicated by the fact that removal of Erbb2 is also expected to affect signaling via ErbB3 and EGF receptors (Barros et al., 2009). In contrast, we (this work) and others (Wen et al., 2010) have shown that ErbB4 ${ }^{-1-}$ and $P V$-Cre;ErbB4 mice are hyperactive in the open field test. To what extent these seemingly disparate findings represent differences in gene targeting strategies (i.e., unconditional vs floxed alleles), strain backgrounds, or other methodological details, is currently not understood. Nevertheless, the increasing evidence for a role of the NRG-1/ErbB4 pathway in regulating dopaminergic function (for review, see Buonanno, 2010), together with data indicating that NRG-1 hypomorphic mice are also hyperactive (Gerlai et al., 2000; Stefansson et al., 2002; Duffy et al., 2008; O’Tuathaigh et al., 2010) and that activity in the open field is a good indicator of nigrostriatal dopaminergic state, provides a possible neurochemical link between ErbB4 and spontaneous locomotor activity.

Deficits in sensorimotor gating have been observed in all ErbB4 mutant mouse strains thus far tested in PPI, including full, PVrestricted, and double Erbb2/Erbb4 mutant mice (Chen et al., 2008; Barros et al., 2009; this work). Moreover, some studies showed reduced PPI in different NRG-1 hypomorphic mouse strains targeting all isoforms ( $\triangle \mathrm{EGF}$ ) or specific subsets of NRG-1 variants (for review, see van den Buuse, 2010), in particular of NRG-1 type III, the predominating NRG-1 isoform in the adult brain (Chen et al., 2008). In aggregate, these findings attest to the significant contribution of the NRG/ErbB4 signaling pathway to neural processes underlying normal gating responses. PPI deficits are widely regarded endophenotypic for schizophrenia and PPI is sensitive to treatments generating hyperdopaminergic and hypoglutamatergic states (Braff, 2010; van den Buuse, 2010). The finding that PV interneuron-restricted ErbB4 mutant mice replicate the hyperactivity and sensorimotorgating phenotypes of full $\mathrm{ErbB} 4^{-1-}$ mice emphasizes the significant contribution of the NRG-1/ErbB4 pathway for normal function of PV interneurons.

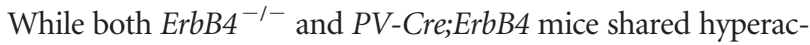
tivity and PPI deficits, a divergent phenotypic outcome was observed in behavioral tasks assessing anxiety and fear. While Erbb4 ${ }^{-/-}$mice exhibited deficits in the elevated plus maze and in cued and contextual fear conditioning, $P V$-Cre;ErbB4 mice were not different from their control littermates in these tasks. Only one other study investigated the effects of genetically ablating ErbB4 signaling on emotional learning and reported reduced contextual fear conditioning in mice with targeted ErbB4 mutations in PV interneurons, a finding that was interpreted as indicative of abnormal LTP regulation in the hippocampus of these mice (Chen et al., 2010). While we presently cannot satisfactorily explain the discrepancy between our groups, the fact that we observed deficits in both cued and contextual fear

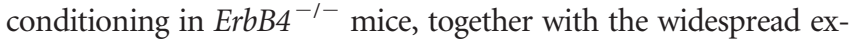
pression of ErbB4 in the amygdala, in particular in the BMA, is consistent with the notion that NRG/ErbB4 signaling in the amygdala is important for emotional learning. The lack of such deficits in PV-Cre:ErbB4 mutant mice is consistent with the relatively sparse distribution of $\mathrm{PV}$ interneurons in the amygdala and our finding that most ErbB4-expressing neurons in the amygdala do not coexpress PV. More refined histological analyses of ErbB4 expression in the amygdala and Erbb4 targeting strategies will be required to identify the pertinent neuron types and signaling processes involved in NRG/ErbB4-mediated regulation of fear behavior.

\section{References}

Allen Brain Atlas [Internet]. Seattle (WA): Allen Institute for Brain Science. (C)2009. Available from: http://www.brain-map.org.

Anton ES, Ghashghaei HT, Weber JL, McCann C, Fischer TM, Cheung ID, Gassmann M, Messing A, Klein R, Schwab MH, Lloyd KC, Lai C (2004) Receptor tyrosine kinase ErbB4 modulates neuroblast migration and placement in the adult forebrain. Nat Neurosci 7:1319-1328.

Barros CS, Calabrese B, Chamero P, Roberts AJ, Korzus E, Lloyd K, Stowers L, Mayford M, Halpain S, Müller U (2009) Impaired maturation of dendritic spines without disorganization of cortical cell layers in mice lacking NRG1/ErbB signaling in the central nervous system. Proc Natl Acad Sci U S A 106:4507-4512.

Benes FM, Berretta S (2001) GABAergic interneurons: implications for understanding schizophrenia and bipolar disorder. Neuropsychopharmacology 25:1-27.

Bjarnadottir M, Misner DL, Haverfield-Gross S, Bruun S, Helgason VG, Stefansson H, Sigmundsson A, Firth DR, Nielsen B, Stefansdottir R, Novak TJ, Stefansson K, Gurney ME, Andresson T (2007) Neuregulin1 (NRG1) signaling through Fyn modulates NMDA receptor phosphorylation: differential synaptic function in NRG1 ${ }^{+/-}$knock-outs compared with wild-type mice. J Neurosci 27:4519-4529.

Braff DL (2010) Prepulse inhibition of the startle reflex: a window on the brain in schizophrenia. Curr Top Behav Neurosci 4:349-371.

Buonanno A (2010) The neuregulin signaling pathway and schizophrenia: from genes to synapses and neural circuits. Brain Res Bull 83:122-131.

Buonanno A, Fischbach GD (2001) Neuregulin and ErbB receptor signaling pathways in the nervous system. Curr Opin Neurobiol 11:287-296.

Chen YJ, Johnson MA, Lieberman MD, Goodchild RE, Schobel S, Lewandowski N, Rosoklija G, Liu RC, Gingrich JA, Small S, Moore H, 
Dwork AJ, Talmage DA, Role LW (2008) Type III neuregulin-1 is required for normal sensorimotor gating, memory-related behaviors, and corticostriatal circuit components. J Neurosci 28:6872-6883.

Chen YJ, Zhang M, Yin DM, Wen L, Ting A, Wang P, Lu YS, Zhu XH, Li SJ, Wu CY, Wang XM, Lai C, Xiong WC, Mei L, Gao TM (2010) ErbB4 in parvalbumin-positive interneurons is critical for neuregulin 1 regulation of long-term potentiation. Proc Natl Acad Sci U S A 107:21818-21823.

Coyle JT (2006) Glutamate and schizophrenia: beyond the dopamine hypothesis. Cell Mol Neurobiol 26:365-384.

del Río JA, de Lecea L, Ferrer I, Soriano E (1994) The development of parvalbumin-immunoreactivity in the neocortex of the mouse. Brain Res Dev Brain Res 81:247-259.

Duffy L, Cappas E, Scimone A, Schofield PR, Karl T (2008) Behavioral profile of a heterozygous mutant mouse model for EGF-like domain neuregulin 1. Behav Neurosci 122:748-759.

Erickson SL, O'Shea KS, Ghaboosi N, Loverro L, Frantz G, Bauer M, Lu LH, Moore MW (1997) ErbB3 is required for normal cerebellar and cardiac development: a comparison with ErbB2-and heregulin-deficient mice. Development 124:4999-5011.

Fazzari P, Paternain AV, Valiente M, Pla R, Luján R, Lloyd K, Lerma J, Marín O, Rico B (2010) Control of cortical GABA circuitry development by Nrg1 and ErbB4 signalling. Nature 464:1376-1380.

Fisahn A, Neddens J, Yan L, Buonanno A (2009) Neuregulin-1 modulates hippocampal gamma oscillations: implications for schizophrenia. Cereb Cortex 19:612-618.

Flames N, Long JE, Garratt AN, Fischer TM, Gassmann M, Birchmeier C, Lai C, Rubenstein JL, Marín O (2004) Short- and long-range attraction of cortical GABAergic interneurons by neuregulin-1. Neuron 44:251-261.

Fox IJ, Kornblum HI (2005) Developmental profile of ErbB receptors in murine central nervous system: implications for functional interactions. J Neurosci Res 79:584-597.

Gassmann M, Casagranda F, Orioli D, Simon H, Lai C, Klein R, Lemke G (1995) Aberrant neural and cardiac development in mice lacking the ErbB4 neuregulin receptor. Nature 378:390-394.

Gerecke KM, Wyss JM, Karavanova I, Buonanno A, Carroll SL (2001) ErbB transmembrane tyrosine kinase receptors are differentially expressed throughout the adult rat central nervous system. J Comp Neurol 433:86-100.

Gerlai R, Pisacane P, Erickson S (2000) Heregulin, but not ErbB2 or ErbB3, heterozygous mutant mice exhibit hyperactivity in multiple behavioral tasks. Behav Brain Res 109:219-227.

Geyer MA (2008) Developing translational animal models for symptoms of schizophrenia or bipolar mania. Neurotox Res 14:71-78.

Golub MS, Germann SL, Lloyd KC (2004) Behavioral characteristics of a nervous system-specific ErbB4 knock-out mouse. Behav Brain Res 153:159-170.

Hippenmeyer S, Vrieseling E, Sigrist M, Portmann T, Laengle C, Ladle DR, Arber S (2005) A developmental switch in the response of DRG neurons to ETS transcription factor signaling. PLoS Biol 3:e159.

Huang YZ, Won S, Ali DW, Wang Q, Tanowitz M, Du QS, Pelkey KA, Yang DJ, Xiong WC, Salter MW, Mei L (2000) Regulation of neuregulin signaling by PSD-95 interacting with ErbB4 at CNS synapses. Neuron 26:443-455.

Kehrer C, Maziashvili N, Dugladze T, Gloveli T (2008) Altered excitatoryinhibitory balance in the NMDA-hypofunction model of schizophrenia. Front Mol Neurosci 1:6.

Kim CH, Lisman JE (1999) A role of actin filament in synaptic transmission and long-term potentiation. J Neurosci 19:4314-4324.

Kwon JS, O'Donnell BF, Wallenstein GV, Greene RW, Hirayasu Y, Nestor PG, Hasselmo ME, Potts GF, Shenton ME, McCarley RW (1999) Gamma frequency-range abnormalities to auditory stimulation in schizophrenia. Arch Gen Psychiatry 56:1001-1005.

Kwon OB, Longart M, Vullhorst D, Hoffman DA, Buonanno A (2005) Neuregulin-1 reverses long-term potentiation at CA1 hippocampal synapses. J Neurosci 25:9378-9383.

Kwon OB, Paredes D, Gonzalez CM, Neddens J, Hernandez L, Vullhorst D, Buonanno A (2008) Neuregulin-1 regulates LTP at CA1 hippocampal synapses through activation of dopamine D4 receptors. Proc Natl Acad Sci U S A 105:15587-15592.

Lai C, Lemke G (1991) An extended family of protein-tyrosine kinase genes differentially expressed in the vertebrate nervous system. Neuron 6:691-704.

Law AJ, Shannon Weickert C, Hyde TM, Kleinman JE, Harrison PJ (2004)
Neuregulin-1 (NRG-1) mRNA and protein in the adult human brain. Neuroscience 127:125-136.

Lewis DA, Hashimoto T, Volk DW (2005) Cortical inhibitory neurons and schizophrenia. Nat Rev Neurosci 6:312-324.

Lisman JE, Coyle JT, Green RW, Javitt DC, Benes FM, Heckers S, Grace AA (2008) Circuit-based framework for understanding neurotransmitter and risk gene interactions in schizophrenia. Trends Neurosci 31:234-242.

Longart M, Liu Y, Karavanova I, Buonanno A (2004) Neuregulin-2 is developmentally regulated and targeted to dendrites of central neurons. J Comp Neurol 472:156-172.

Madisen L, Zwingman TA, Sunkin SM, Oh SW, Zariwala HA, Gu H, Ng LL, Palmiter RD, Hawrylycz MJ, Jones AR, Lein ES, Zeng H (2010) A robust and high-throughput Cre reporting and characterization system for the whole mouse brain. Nat Neurosci 13:133-140.

Mei L, Xiong WC (2008) Neuregulin 1 in neural development, synaptic plasticity and schizophrenia. Nat Rev Neurosci 9:437-452.

Nason MW Jr, Adhikari A, Bozinoski M, Gordon JA, Role LW (2011) Disrupted activity in the hippocampal-accumbens circuit of type III neuregulin 1 mutant mice. Neuropsychopharmacology 36:488-496.

Neddens J, Buonanno A (2010) Selective populations of hippocampal interneurons express ErbB4 and their number and distribution is altered in ErbB4 knock-out mice. Hippocampus 20:724-744.

Neddens J, Fish KN, Tricoire L, Vullhorst D, Shamir A, Chung W, Lewis DA, McBain CJ, Buonanno A (2011) Conserved interneuron-specific ErbB4 expression in frontal cortex of rodents, monkeys, and humans: implications for schizophrenia. Biol Psychiatry 70:636-645.

O’Tuathaigh CM, Harte M, O'Leary C, O'Sullivan GJ, Blau C, Lai D, Harvey RP, Tighe O, Fagan AJ, Kerskens C, Reynolds GP, Waddington JL (2010) Schizophrenia-related endophenotypes in heterozygous neuregulin-1 'knockout' mice. Eur J Neurosci 31:349-358.

Phillips RG, LeDoux JE (1992) Differential contribution of amygdala and hippocampus to cued and contextual fear conditioning. Behav Neurosci 106:274-285.

Pitcher GM, Kalia LV, Ng D, Goodfellow NM, Yee KT, Lambe EK, Salter MW (2011) Schizophrenia susceptibility pathway neuregulin 1-ErbB4 suppresses Src upregulation of NMDA receptors. Nat Med 17:470-478.

Stäubli U, Chun D (1996) Factors regulating the reversibility of long-term potentiation. J Neurosci 16:853-860.

Stefansson H, Sigurdsson E, Steinthorsdottir V, Bjornsdottir S, Sigmundsson T, Ghosh S, Brynjolfsson J, Gunnarsdottir S, Ivarsson O, Chou TT, Hjaltason O, Birgisdottir B, Jonsson H, Gudnadottir VG, Gudmundsdottir E, Bjornsson A, Ingvarsson B, Ingason A, Sigfusson S, Hardardottir H, et al. (2002) Neuregulin 1 and susceptibility to schizophrenia. Am J Hum Genet 71:877-892.

Steiner H, Blum M, Kitai ST, Fedi P (1999) Differential expression of ErbB3 and ErbB4 neuregulin receptors in dopamine neurons and forebrain areas of the adult rat. Exp Neurol 159:494-503.

Stephan KE, Baldeweg T, Friston KJ (2006) Synaptic plasticity and dysconnection in schizophrenia. Biol Psychiatry 59:929-939.

Tidcombe H, Jackson-Fisher A, Mathers K, Stern DF, Gassmann M, Golding JP (2003) Neural and mammary gland defects in ErbB4 knockout mice genetically rescued from embryonic lethality. Proc Natl Acad Sci U S A 100:8281-8286.

Uhlhaas PJ, Singer W (2010) Abnormal neural oscillations and synchrony in schizophrenia. Nat Rev Neurosci 11:100-113.

van den Buuse M (2010) Modeling the positive symptoms of schizophrenia in genetically modified mice: pharmacology and methodology aspects. Schizophr Bull 36:246-270.

Vullhorst D, Neddens J, Karavanova I, Tricoire L, Petralia RS, McBain CJ, Buonanno A (2009) Selective expression of ErbB4 in interneurons, but not pyramidal cells, of the rodent hippocampus. J Neurosci 29:12255-12264.

Wen L, Lu YS, Zhu XH, Li XM, Woo RS, Chen YJ, Yin DM, Lai C, Terry AV Jr, Vazdarjanova A, Xiong WC, Mei L (2010) Neuregulin 1 regulates pyramidal neuron activity via ErbB4 in parvalbumin-positive interneurons. Proc Natl Acad Sci U S A 107:1211-1216.

Wilson TW, Hernandez OO, Asherin RM, Teale PD, Reite ML, Rojas DC (2008) Cortical gamma generators suggest abnormal auditory circuitry in early-onset psychosis. Cereb Cortex 18:371-378.

Yau HJ, Wang HF, Lai C, Liu FC (2003) Neural development of the neuregulin receptor ErbB4 in the cerebral cortex and the hippocampus: preferential expression by interneurons tangentially migrating from the ganglionic eminences. Cereb Cortex 13:252-264. 